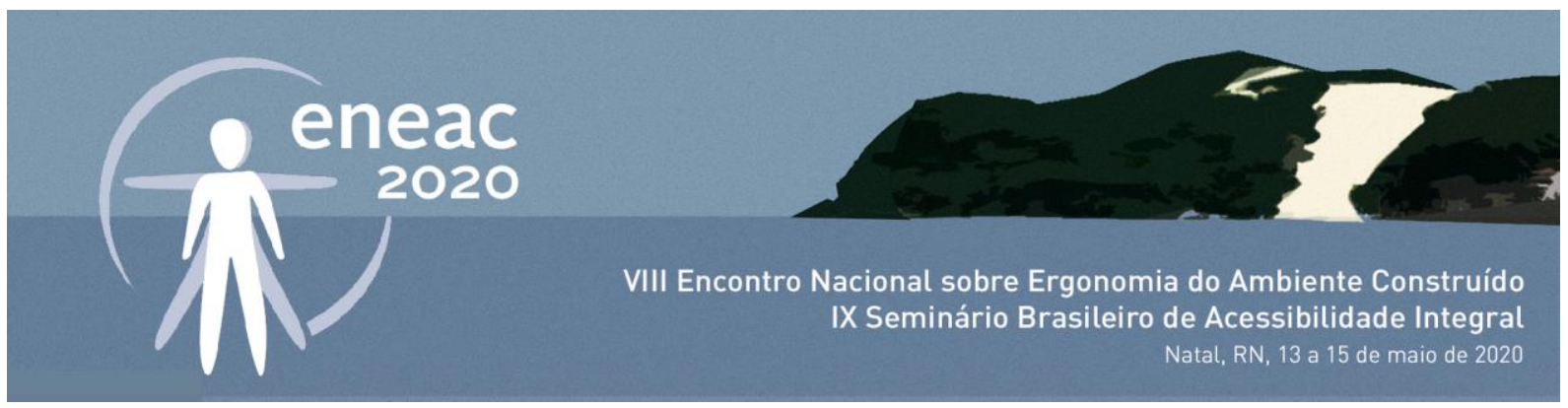

\title{
Predição e avaliação da preferência percebida em salas de aula
}

\section{Prediction and assessment of perceived preference in classrooms}

\author{
SHEILA RODRIGUES DE ALBUQUERQUE \\ Mestranda em Design, UFPE (PPGDesign), sheilaarq1@gmail.com
}

LOURIVAL COSTA FILHO

Dr. em Desenvolvimento Urbano, UFPE (NDC | PPGDesign | PPErgo), lourivalcosta@yahoo.com

\section{RESUMO}

Este artigo visa apresentar categorias preditoras da preferência humana por ambientes, e examinar os efeitos de algumas dessas categorias na avaliação da preferência percebida em cenas de salas de aula. A partir desses objetivos, tomou-se duas categorias - coerência e complexidade - como variáveis a serem testadas em uma investigação empírica estruturada através de uma Sentença Estruturadora, instrumento básico da Teoria das Facetas, e elegeram-se o Sistema de Classificações Múltiplas para coletar os dados e uma tabela de distribuição das frequências para analisá-los. Entre os resultados obtidos, apurou-se que a preferência percebida, em cenas de sala de aula, é revelada com o contraste alto (coerência baixa) e a complexidade máxima, diferente do que a teoria sugere, sendo omitida com o contraste baixo (coerência alta) e a complexidade mínima, corroborando com as predições teóricas.

PALAVRAS-CHAVES: sala de aula, coerência, complexidade, preferência ambiental, ergonomia do ambiente construído.

\begin{abstract}
This article aims to present predict categories human preference for environments and to examine the effects of some of these categories on the assessment of perceived preference in classroom scenes. From these objectives, it took two categories - coherence and complexity - as variables to be tested in an empirical investigation designed through a Mapping Sentence, a basic instrument of Facet Theory, and chose the Multiple Sorting Procedure to collect the data and a frequency distribution table to analyse them. Among the results obtained, it was found that perceived preference in classroom scenes is revealed with high contrast (low coherence) and maximum complexity, different from what the theory suggests, being omitted with low contrast (high coherence) and minimal complexity, corroborating with theoretical predictions.
\end{abstract}

KEYWORDS: classroom, coherence, complexity, environmental preference, ergonomics of the built environment. 


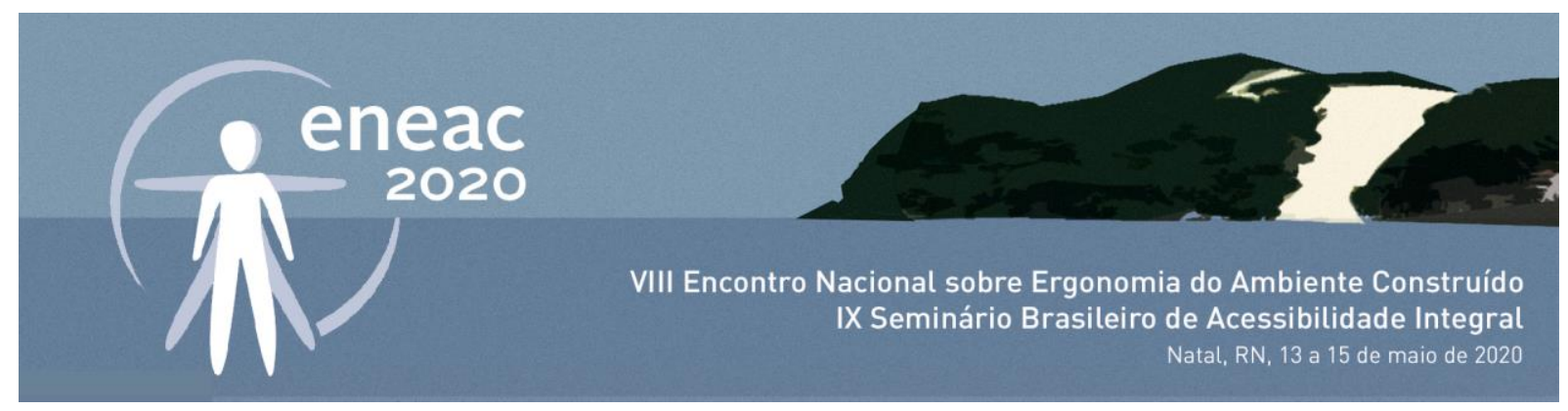

\section{INTRODUÇÃO}

O meio físico, conforme Elali (2003 apud HORNE, 1999, LOUREIRO, 1990), tem impacto direto e simbólico sobre seus ocupantes, facilitando e/ou inibindo comportamentos. Na escola, ele possibilita a decodificação e a aprendizagem até mesmo de normas sociais, comunicando não-verbalmente aos estudantes as intenções e os valores dos professores que exercem controle sobre o espaço.

Em relação ao contexto do espaço da sala de aula, pode-se afirmar, de acordo com Kowaltowski et al. (2001), que eles são importantes para a promoção de estímulos e de comportamentos relevantes aos seus usuários. Além disso, dependendo dos níveis de participação dos alunos no ambiente escolar, para esses autores, normalmente passam-se muito tempo nesse tipo de espaço.

Em vista disso, conforme Kowaltowski (2011), a infraestrutura dos ambientes é essencial na fase da idade escolar, porque é nesse momento que se inicia o processo de socialização do indivíduo, e, por esse motivo, o ambiente deverá contribuir para o processo de aprendizagem. Sanoff (2001) acrescenta que o ambiente de sala de aula contribui para a aprendizagem quando é cuidadosamente projetado e busca atender às necessidades individuais, tanto de professores como de alunos.

Tem-se, portanto, que as decisões projetuais para ambientes de salas de aula têm efeitos sobre as questões do ensino-aprendizagem, considerando que o espaço projetado será a interface que permitirá trocas e proporcionará a adequação do ambiente às ações que ali ocorrem, o que aponta para um enfoque nos domínios da ergonomia do ambiente construído (ACIOLI; COSTA FILHO, 2019).

A ergonomia do ambiente construído considera, de maneira aprofundada, a avaliação das características ambientais em relação aos propósitos e às ações dirigidas aos objetivos humanos que neles recaem e, como tal, leva em conta a percepção e o comportamento de seus ocupantes.

Nesse contexto, no âmbito da ergonomia do ambiente construído, as avaliações do ambiente relacionam-se com fenômenos de ordem subjetiva, além daqueles de ordem física e organizacional, relacionadas com as características ambientais, podendo interferir no desempenho do usuário na realização das tarefas que neles são desenvolvidas.

Corroborando com essa visão, Moraes (2004) expôs que projetar espaços não significa apenas considerar necessidades funcionais, como conforto e segurança, mas, para além disso, necessidades estéticas, e assim promover no ambiente, a agradabilidade, o prazer e o bem-estar aos usuários.

Para o ambiente da sala de aula, pode-se argumentar que a recomendação de considerar conceitos de usabilidade, como acima formulados, seria um resultado desejável, já que as pessoas nem sempre podem opinar ou escolher onde preferem estudar, além do fato de Bernardes (2019), apoiando-se em diversas pesquisas, relatar que os parâmetros ergonômicos dos elementos do ambiente escolar estão inadequados na sala de aula, comprometendo além da saúde o desempenho escolar.

Nesse contexto, a investigação empírica aqui apresentada, partindo da formulação de uma Sentença Estruturadora Geral, instrumento básico da Teoria das Facetas (TF), foi estruturada e tomou como categorias (facetas) duas características ambientais de salas de aula, complexidade e coerência, pelas suas possíveis influências na preferência por ambientes e, sobretudo por se relacionarem com os elementos ambientais de modo abrangente, como se preconiza para as abordagens ergonômicas.

Apesar de haver um referencial teórico abrangente, no que se refere à abordagem na literatura sobre o ambiente de sala de aula, as análises empíricas sobre as características dos elementos desse 


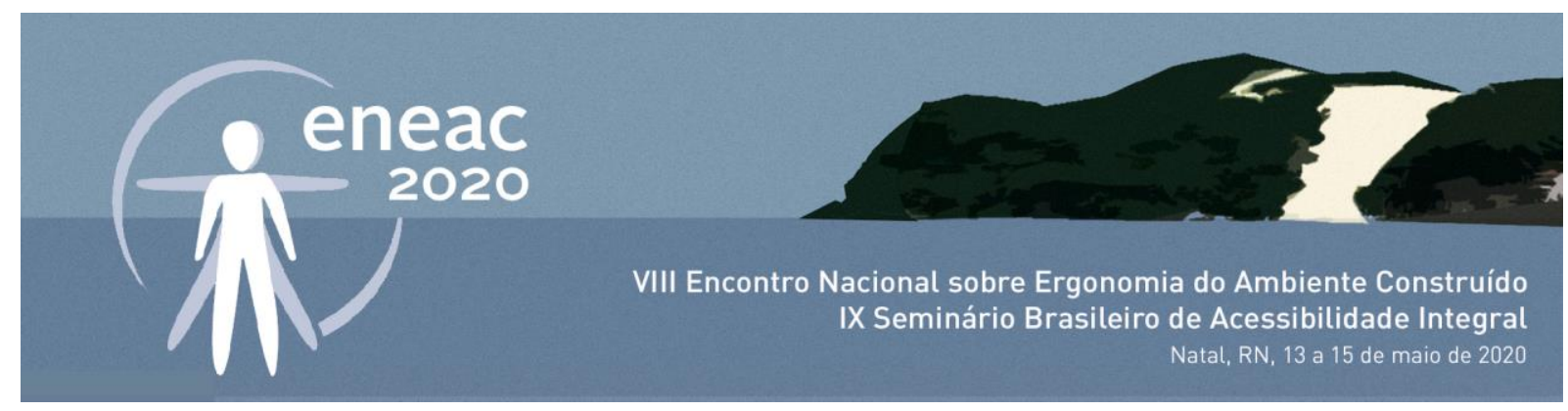

tipo de ambiente, geralmente ficam para trás. Assim sendo, visando contribuir com as lacunas listadas, a pesquisa apresentada neste artigo teve como principais objetivos: identificar categorias preditoras da preferência humana por ambientes e examinar os efeitos de algumas dessas categorias selecionadas na preferência percebida em cenas de salas de aula. A partir dos resultados obtidos, busca-se, ainda, de forma secundária, propor algumas recomendações projetuais.

Pautada em bases científicas da estética ambiental e da ergonomia do ambiente construído, esses objetivos propostos visam contribuir com diretrizes de projetos que auxiliem na definição das características dos elementos de salas de aula, na medida em que, presumivelmente, a avaliação ambiental influencia o comportamento, de modo que as pessoas têm maior probabilidade de frequentar um local percebido como favorável, e evitar outro percebido como desfavorável.

Antes de finalizar esta primeira sessão, cumpre apenas destacar que, segundo Nasar (1988), a Estética Ambiental representa a fusão de duas áreas de investigação: a Estética Empírica e a Psicologia Ambiental, que usam metodologias científicas para tentar explicar o estímulo físico e a resposta humana. Enquanto a estética empírica se preocupa com as artes, a psicologia ambiental foca na melhoria da qualidade do habitat humano. Assim, para o autor, combinando a preocupação com o valor estético, o problema focalizado no habitat humano e a ênfase metodológica na aplicabilidade, a Estética Ambiental se torna um empreendimento único para a avaliação de lugares.

\section{REFERENCIAL TEÓRICO}

O ambiente construído da escola deve estar preparado para atualizações necessárias, para atender novos comportamentos, novas atividades e novas aprendizagens. Essas mudanças invariavelmente envolvem tecnologia e maior autonomia do estudante (SARMENTO; VILLAROUCO, 2018).

Para Oliveira e Mont'Alvão (2015), são os elementos ambientais que devem ser considerados pela Ergonomia do Ambiente Construído, pois se referem ao conforto ambiental (lumínico, térmico, acústico), à percepção ambiental (aspectos cognitivos), adequação de materiais (revestimentos, acabamentos), cores e texturas, acessibilidade, e dados antropométricos (layout, dimensionamento).

A ergonomia, como a tecnologia projetual das comunicações entre humanos e máquinas, trabalho e ambiente está interessada em contribuir com pesquisas sobre novas formas de pensar o projeto do ambiente de trabalho (MORAES; MONT'ALVÃO, 2009), que, nesta pesquisa, é o ambiente de sala de aula, esforçando-se para que bons resultados sejam obtidos.

Sanoff (2001) recomenda que se avalie os aspectos do projeto escolar de forma conjunta com todos os usuários e reforça que a imagem da escola e da sala de aula são os aspectos prioritários.

A imagem avaliativa surge da pessoa e do ambiente, e da continua interação entre os dois, podendo variar a partir de fatores humanos e das características ambientais. Os observadores, dependendo desses fatores internos e ambientais, ignoram algumas características espaciais, prestam atenção a outras e avaliam o que veem. Essa avaliação envolve sentimentos relacionados à estrutura do ambiente e também do significado do conteúdo dele. Em suma, filtra-se a resposta avaliativa pelas lentes de julgamentos perceptivos/cognitivos, e de outros afetivos/emocionais para o ambiente (NASAR, 1998), e, como consequência, levam seus ocupantes a agir sobre os fatores que o definem.

Embora várias culturas e indivíduos possam ter experiências únicas com seu ambiente, o processo subjacente às suas avaliações e os elementos nela considerados têm muito em comum. Pesquisas 


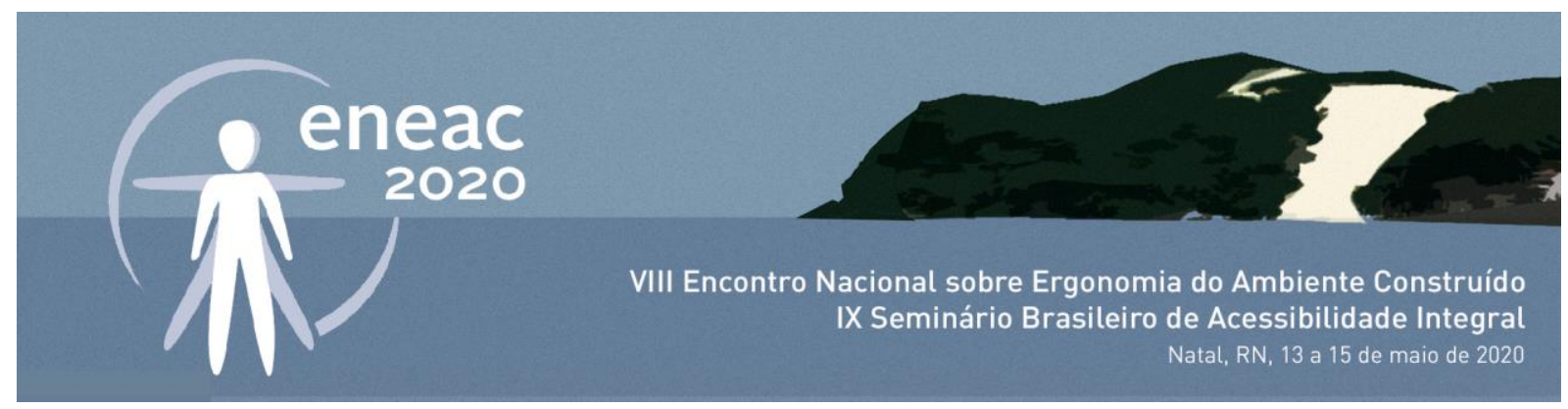

apontam para seis tipos de características visuais relacionadas à preferência: coerência, complexidade moderada, natureza, manutenção, abertura, e significado histórico (NASAR, 2008).

As áreas avaliadas positivamente tendem a ter esses atributos; já as avaliadas de modo negativo têm seus opostos - incoerência, complexidade mínima ou máxima, artificialidade, dilapidação, obstrução visual, e ausência de significado histórico. Ordem, complexidade e abertura representam variáveis formais; enquanto naturalidade, manutenção e significado histórico representam variáveis de conteúdo ou simbólicas, mas essas categorias ainda permanecem pouco claras.

Com vistas à preferência ambiental, Kaplan e Kaplan (1989) definiram em uma teoria relacionada com a sobrevivência humana, que há uma predisposição para ambientes com coerência e complexidade, na medida em que, respectivamente, a primeira característica ajuda o ser humano a compreendê-los; e a segunda favorece o envolvimento.

Em relação à coerência (obtida pela redução do contraste), as pessoas tendem a preferir ambientes que promovem ordem visual, compatibilidade e compreensão, para que se possa atuar neles. Essa característica, portanto, tem emergido como uma dimensão proeminente da resposta humana para o entorno, e as pesquisas consistentemente encontram a preferência associada com a coerência. Assim, é sugerido que a coerência alta eleva a preferência por ambientes, que é reduzida para a coerência média (contraste alto), sendo menor para a coerência baixa (contraste alto) da cena.

A complexidade igualmente aparece consistentemente como uma dimensão proeminente da resposta avaliativa para ambientes. Essa variável, também conhecida como riqueza visual, ornamentação, taxa de informação, diversidade e variedade, envolve o número de elementos diferentes e a distinção entre esses elementos em uma cena. Cenas com poucos elementos, ou muitos elementos semelhantes, parecem relativamente mais simples do que outras com muitos elementos distintos. As pesquisas sobre a preferência por ambientes geralmente sugerem a complexidade moderada como estando mais associada a esse resultado (NASAR, 2000). Em um estudo de várias cenas de ambientes, Wohlwill (1976), corroborando os resultados pioneiros de Berlyne (1972) para a preferência visual por imagens, encontrou também a preferência como tendo a forma de " $U$ " invertido em relação à complexidade, ou seja, o nível intermediário de complexidade seria preferido em relação aos ambientes com complexidade mínima e máxima. Considerando alguns vieses, observados em outras pesquisas, os resultados apontam para uma resposta avaliativa para a preferência ambiental como estando associada à complexidade moderada dos elementos.

Apesar de as respostas avaliativas para a preferência ambiental, por si só, não poderem prever o comportamento real do usuário, a avaliação combinada de respostas avaliativas e do comportamento previsto dá uma boa indicação do comportamento real (NASAR, 1988). Logo, nesta pesquisa, os respondentes foram solicitados a indicar em que medida várias cenas de salas de aula favoreciam estar ou permanecer assistindo às aulas.

\section{MATERIAIS E MÉTODOS}

A Teoria das Facetas (TF), relacionada com o desenho da investigação empírica desta pesquisa, segundo Costa Filho (2014), é um procedimento de pesquisa meta-teórico, criado e desenvolvido por Louis Guttman durante a década de 1950. O intuito inicial foi o de atender aos problemas de pesquisa com relação aos procedimentos estatísticos aplicados nas Ciências Sociais. 


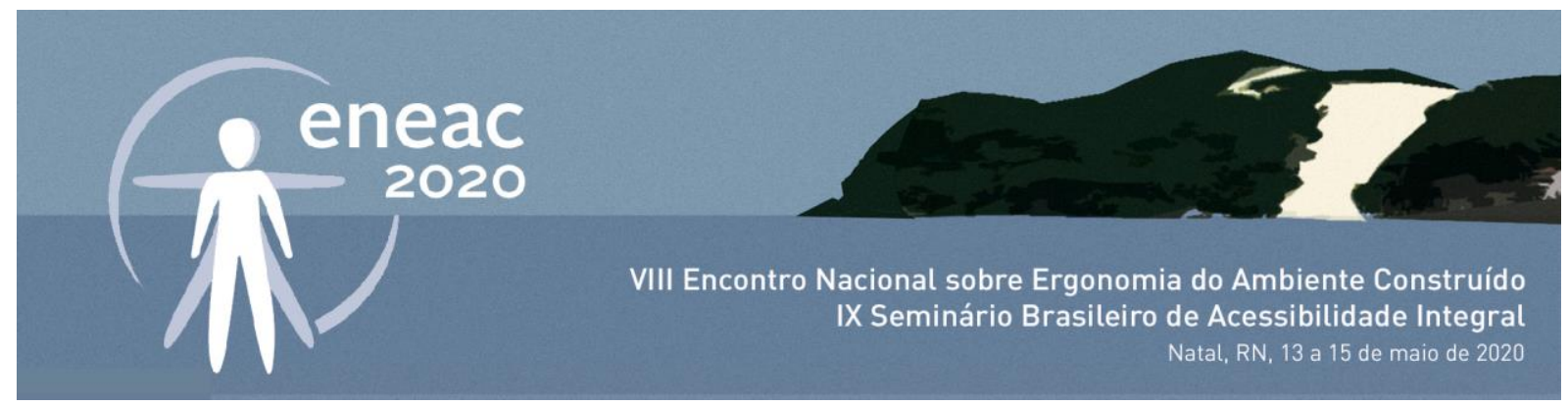

A TF estrutura o delineamento da investigação exploratória em uma sentença semântica, que relaciona os elementos teóricos e empíricos da pesquisa com seus possíveis resultados (SOLOMON, 2019). Essa sentença normalmente reúne três tipos básicos de facetas que representam objetos e/ou variáveis da investigação empírica. Cada faceta é constituída por elementos internos que relacionam de forma exclusiva e abrangente o universo de cada componente da pesquisa (COSTA FILHO, 2014).

Conforme Bilsky (2003), há três tipos básicos de facetas. O primeiro tipo está relacionado aos grupos de indivíduos da pesquisa (população amostral). O segundo tipo descreve o conteúdo das variáveis escolhidas (faceta de conteúdo). O primeiro e o segundo tipos de facetas, juntos, definem o campo de interesse da pesquisa (faceta de domínio). 0 terceiro tipo relaciona-se com as possibilidades de respostas comuns a todas as facetas.

A partir das variáveis selecionadas, contraste e complexidade, bem como de seus elementos internos, definiu-se a Sentença Estruturadora Geral para a avaliação da preferência por cenas de salas de aula (Figura 1), que demonstra de forma inequívoca como essas variáveis foram manipuladas sistematicamente para a avaliação pretendida.

Figura 1. Sentença Estruturadora Geral para a avaliação da preferência em salas de aula

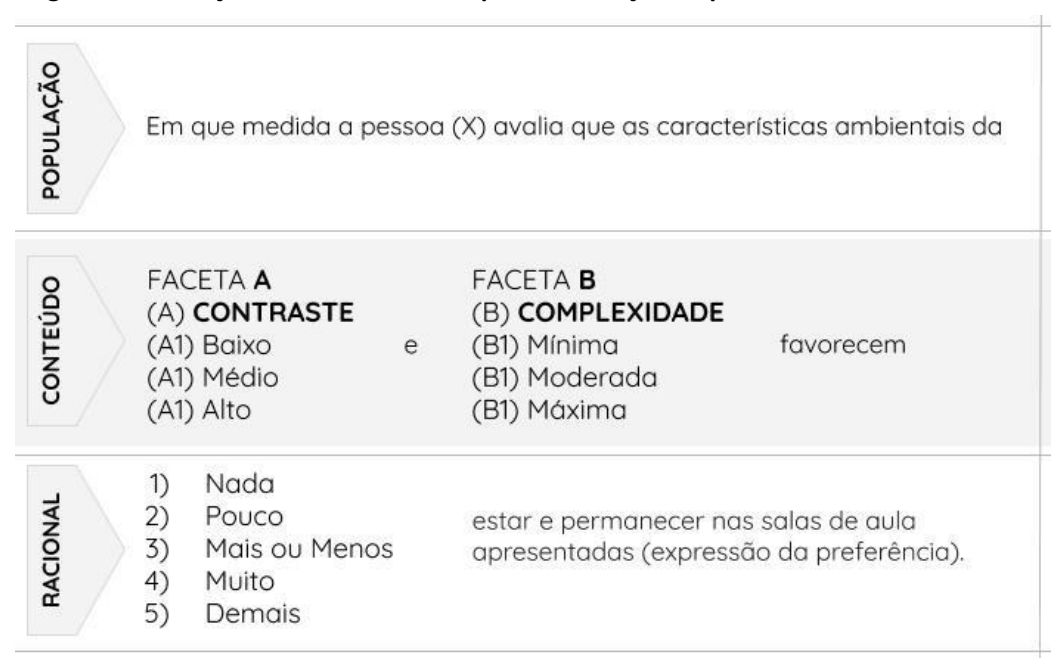

Fonte: Autores (2020)

O primeiro tipo de faceta, população amostral, relaciona-se com os participantes abordados na pesquisa. O segundo tipo, contraste e complexidade, ambas em três diferentes níveis, representam o conteúdo a ser examinado. Para tal, os três elementos internos de cada uma das categorias foram arranjados e mapeados de forma semelhante a uma análise combinatória, produzindo nove diferentes conjuntos ( $\mathrm{X} 3 \times \mathrm{Y} 3=\mathrm{XY9}$ ), que transmitem uma relação ou situação específica a ser avaliada, através de um racional comum a esse domínio, considerando uma escala com cinco pontos (nada, pouco, mais ou menos, muito, demais), relacionada com o terceiro tipo.

Esse conjunto de nove cenas apoiou as avaliações, estando cada uma delas diretamente relacionada às variáveis desta pesquisa, listadas na Sentença Estruturadora Geral para a avaliação da preferência por salas de aula. Cada cena, selecionada no banco de imagens de salas de aula do "Google Imagem", 


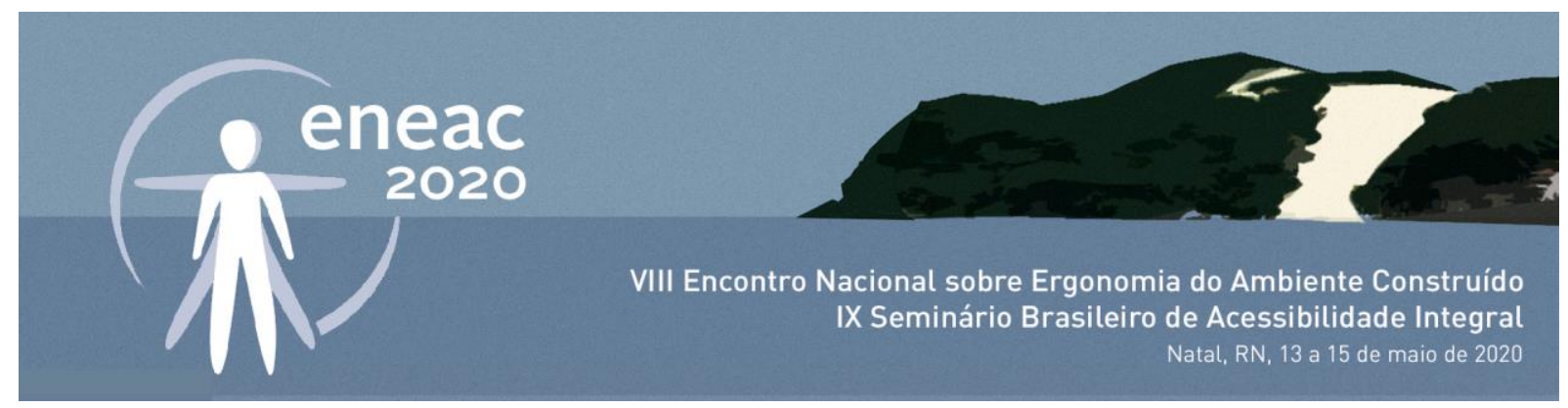

considerando três diferentes níveis de contraste e complexidade (Quadro 1), foram submetidas a um corpo de 5 juízes, alunos do PPGDESIGN/UFPE, buscando o consenso visual para os níveis indicados.

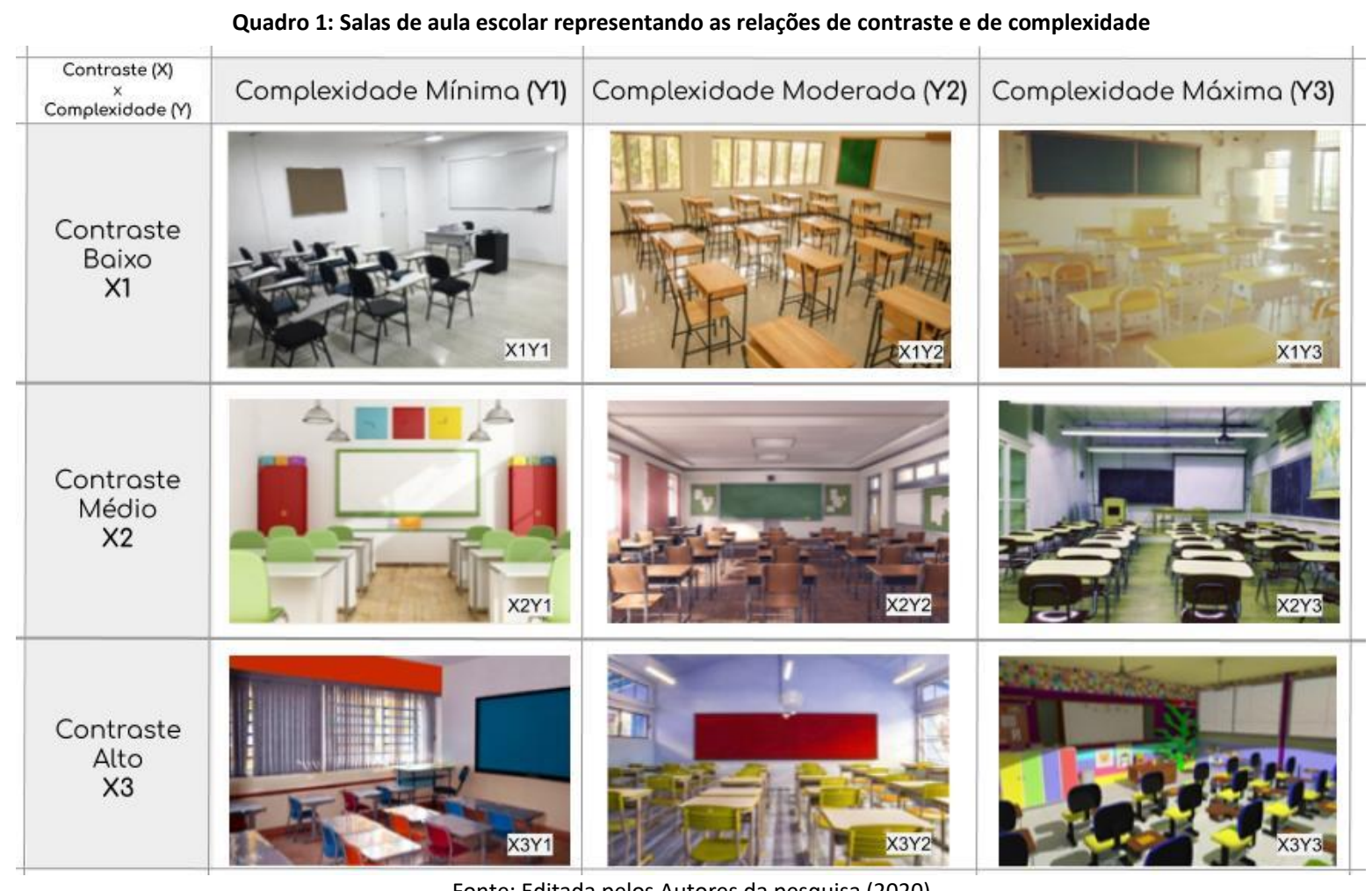

Fonte: Editada pelos Autores da pesquisa (2020)

No que se refere às considerações metodológicas, a pesquisa de campo do tipo exploratório, como definida por Marconi e Lakatos (2003), possibilitou descrições quantitativas do objeto de estudo empírico, e os pesquisadores puderam conceituar as inter-relações entre as propriedades das cenas de salas de aula, avaliadas através do Sistema de Classificações Múltiplas (SCM).

O Sistema de Classificações Múltiplas, atualizado por Canter, Brown e Groat (1985) para analises específicas, consiste em pedir aos participantes para classificar os mesmos elementos diversas vezes, através de critérios por eles definidos (classificações livres) ou pelo pesquisador (classificações dirigidas), para entender suas ideias sobre eles. As classificações consideram a similaridade de modo que elementos de uma categoria tenham algo distinto das demais.

Sem o emprego de técnicas probabilísticas de amostragem, foram realizadas classificações dirigidas com 10 participantes, sendo 7 mulheres e 3 homens, entre 25 e 65 anos de idade. Um número relativamente pequeno, mas suficiente para um resultado apenas indicativo da situação-problema.

As entrevistas - todas agendadas previamente - foram realizadas pessoalmente, e os participantes, após informar a idade, foram solicitados a classificar as cenas com a seguinte instrução: em que medida você avalia que cada uma dessas cenas favorece estar e permanecer em salas de aula [expressão da preferência por esse tipo de ambiente]. 


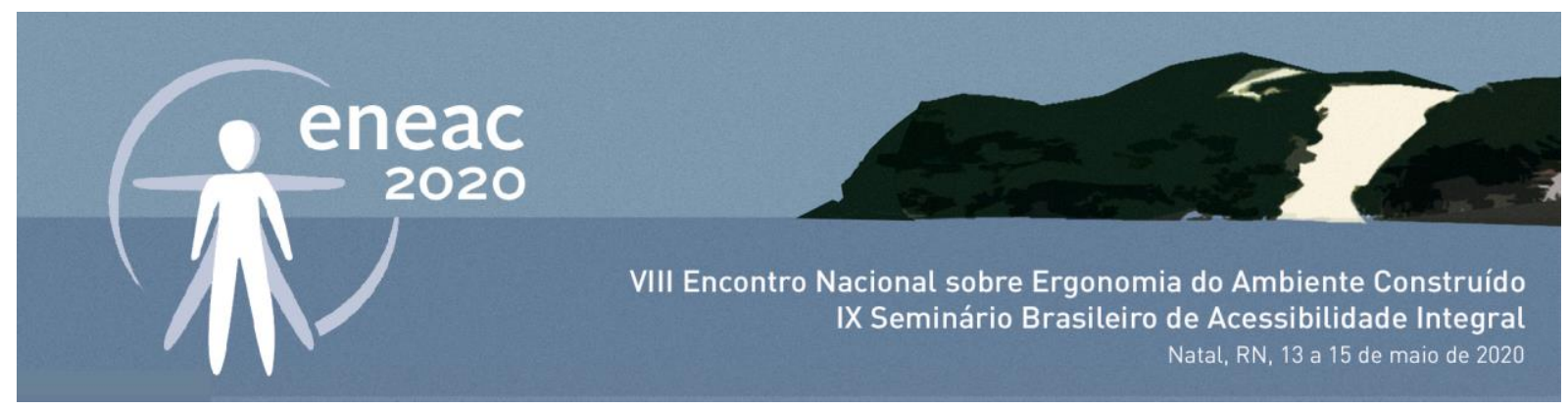

Finalizada a coleta, os dados obtidos foram condensados em uma Tabela de Distribuição das Frequências (MARCONI; LAKATOS,2003), que permite a melhor compreensão dos diferentes dados atribuídos pelos participantes nas classificações dirigidas para as nove cenas de sala de aula, bem como o escore final para cada uma delas, ou seja, a preferência percebida pelos respondentes.

Esse tipo de enfoque para a avaliação de lugares - considerando um contínuo de teorias, procedimento teórico-metodológico, evidências empíricas e aplicações metodológicas - foi apresentado em Costa Filho (2014), e vem se mostrando consistente para a imagem avaliativa de produtos e de ambientes em diversas pesquisas realizadas em parcerias, que validam sua utilização.

\section{RESULTADOS}

A partir da análise dos dados - tabulados para os cinco diferentes pontos da escala proposta - para a resposta avaliativa das nove cenas de salas de aula, foi possível verificar o efeito da complexidade e da coerência desse tipo de ambiente na preferência percebida pelos respondentes (Tabela 2).

Tabela 2: Distribuição das Frequência para as 9 cenas de salas de aula

\begin{tabular}{|c|c|c|c|c|c|c|c|c|c|}
\hline $\begin{array}{r}\text { CENAS } \\
\text { SUJEITOS }\end{array}$ & X1Y1 & X1Y2 & X1Y3 & $\mathrm{X} 2 \mathrm{Y} 1$ & $\mathrm{X} 2 \mathrm{Y} 2$ & $\mathrm{X} 2 \mathrm{Y} 3$ & X3Y1 & X3Y2 & X3Y3 \\
\hline 01 & 1 & 3 & 1 & 4 & 1 & 3 & 5 & 4 & 5 \\
\hline 02 & 2 & 2 & 3 & 2 & 3 & 4 & 2 & 2 & 4 \\
\hline 03 & 1 & 1 & 2 & 3 & 3 & 5 & 2 & 1 & 4 \\
\hline 04 & 1 & 3 & 4 & 2 & 1 & 1 & 4 & 1 & 5 \\
\hline 05 & 3 & 4 & 2 & 3 & 3 & 3 & 2 & 2 & 1 \\
\hline 06 & 3 & 2 & 2 & 4 & 3 & 1 & 3 & 3 & 4 \\
\hline 07 & 4 & 5 & 3 & 5 & 5 & 4 & 4 & 5 & 2 \\
\hline 08 & 3 & 5 & 4 & 4 & 5 & 2 & 4 & 3 & 2 \\
\hline 09 & 2 & 4 & 2 & 5 & 4 & 2 & 3 & 3 & 5 \\
\hline 10 & 3 & 3 & 3 & 4 & 3 & 2 & 5 & 3 & 5 \\
\hline TOTAL & 23 & 32 & 26 & 36 & 31 & 27 & 34 & 27 & 37 \\
\hline
\end{tabular}

As pontuações obtidas omitem os efeitos esperados da coerência (obtida pela redução do contraste) e da complexidade na PREFERÊNCIA por salas de aula, embora esses efeitos esperados tenham sido observados para a situação oposta, ou seja, para a NÃO PREFERÊNCIA por esse tipo de ambiente.

Para o contraste, a preferência foi maior para a cena de sala de aula com contraste alto (baixa coerência), divergindo da situação sugerida, sendo menor para aquela com contraste baixo (alta coerência), corroborando com o resultado previsto. Já para a complexidade, a preferência foi maior para a cena de sala de aula com complexidade máxima, também diferente da situação sugerida, sendo menor para aquela de complexidade mínima, corroborando com o esperado.

A PREFERÊNCIA humana por ambientes, pelo viés teórico, é significantemente aumentada com o contraste baixo, que elevaria a coerência da cena, promovendo ordem visual, compatibilidade e compreensão, e com a complexidade média, uma vez que a complexidade mínima é postulada como monótona e entediante, enquanto a complexidade máxima seria caótica e estressante. 


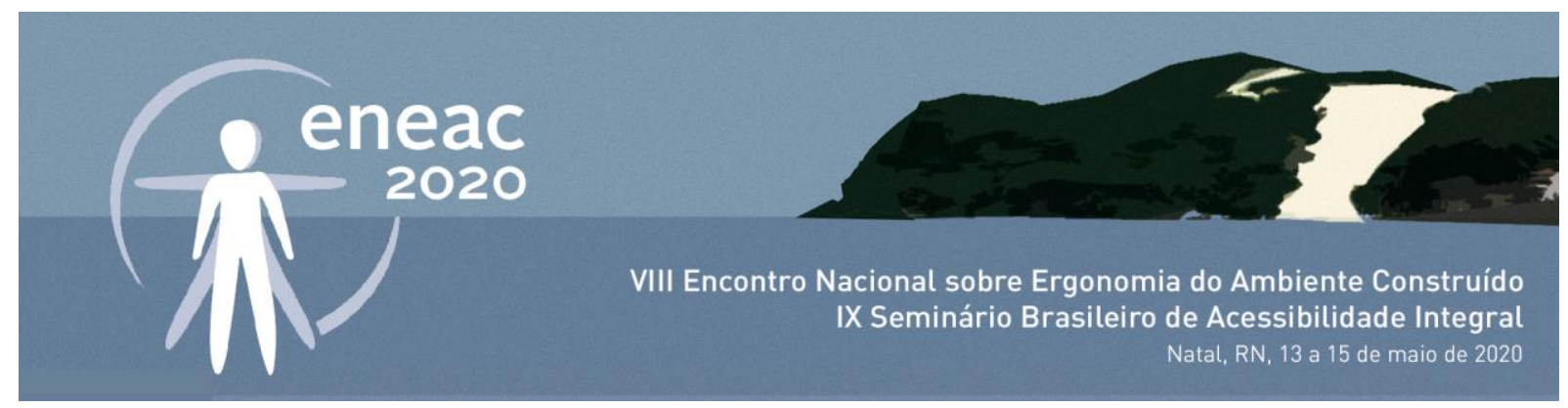

Como mostra a Tabela 1, a cena de número 09 (X3Y3), sala de aula com contraste alto (coerência baixa) e complexidade máxima, foi a PREFERIDA para estar e permanecer em salas de aula, segundo os respondentes (Figura 2). Inversamente, a cena de número 01 (X1Y1), sala de aula com contraste alto (coerência baixa) e complexidade mínima, foi a PRETERIDA para a mesma situação (Figura 2).

Figura 2: a preferência em cenas de sala de aula

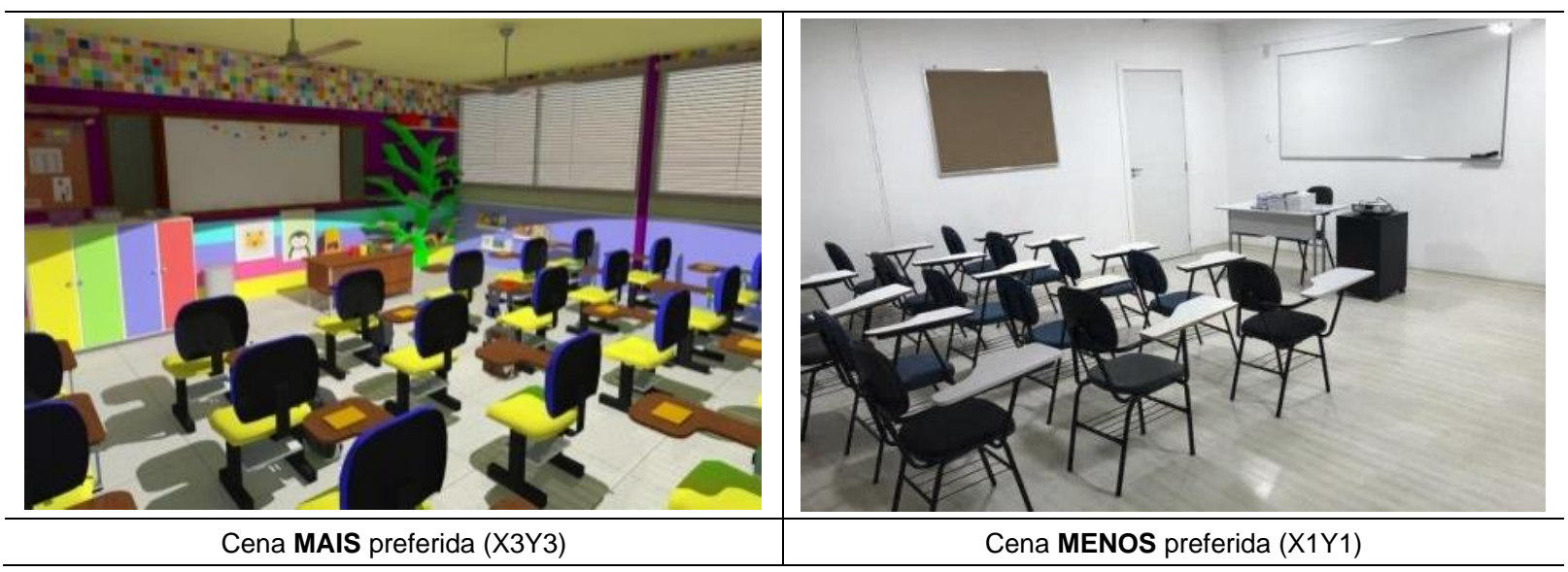

Fonte: Banco de imagens de salas de aula do GOOGLE IMAGEM

Resultado empírico semelhante foi apurado em uma pesquisa que avaliou o efeito da coerência (obtida pela redução do contraste) e da complexidade na agradabilidade percebida em salas de aula para o ensino superior (ACIOLI; COSTA FILHO, 2019), tendo encontrado que agradabilidade percebida nesse tipo de cena era elevada com o contraste alto (coerência baixa) e a complexidade máxima, corroborando com os achados desta pesquisa.

\section{CONCLUSÃO}

Como demonstrado, as decisões projetuais para os ambientes de salas de aula têm efeitos sobre as questões do ensino e da aprendizagem. Por essa razão, é um grande desafio projetar ambientes físicos de salas de aula que favoreçam a interface humano-ambiente.

Identificar categorias preditoras da preferência ambiental e examinar os efeitos da coerência (obtida pela redução do contraste) e da complexidade na preferência percebida por cenas de salas de aula têm importância e justificam-se para a ergonomia do ambiente construído, na medida em criam bases para decisões projetuais para esse tipo de espaço.

Nessa perspectiva, buscando identificar categorias preditoras da preferência ambiental, apurou-se, apoiando-se em Nasar (2008), seis tipos: coerência, complexidade moderada, natureza, manutenção, abertura, e significado histórico. Logo, ambientes avaliados positivamente tendem a ter esses atributos, enquanto aqueles julgados de modo negativo teriam categorias opostas a essas.

Do mesmo modo, no sentido de examinar os efeitos da coerência (obtida pela redução do contraste) e da complexidade na preferência percebida em cenas de salas de aula, concluiu-se que essa 


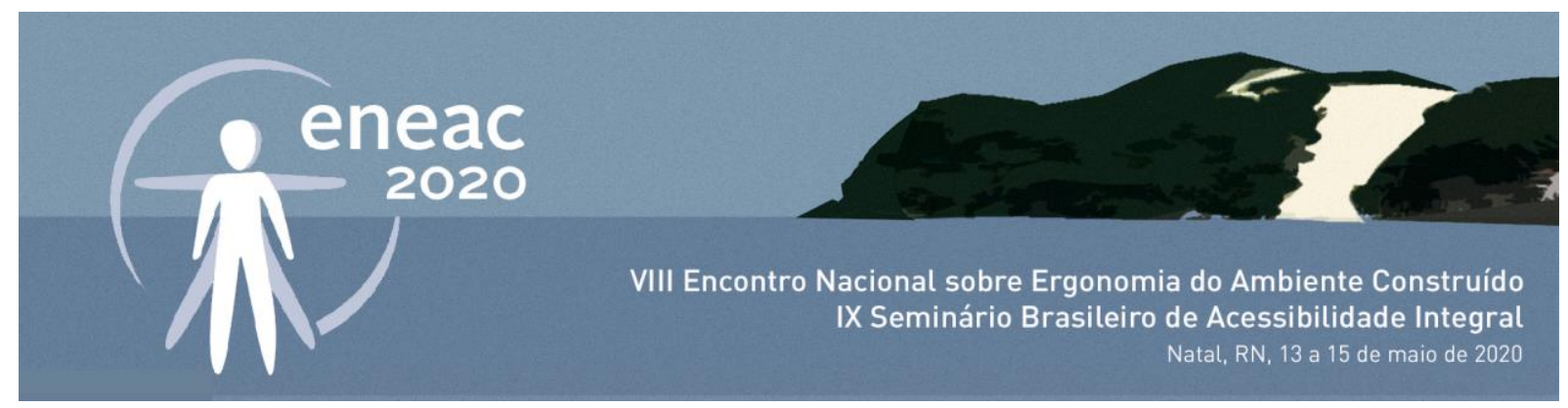

resposta foi associada à cena de sala de aula com contraste alto (coerência baixa) e complexidade máxima; já a cena com contraste baixo (coerência alta) e complexidade mínima revelou o oposto.

A partir desses resultados apurados, e ainda como resposta a um objetivo secundário, para que as características de contraste e de complexidade de salas de aula favoreçam a preferência percebida por seus ocupantes, o contraste alto (coerência baixa) e a complexidade máxima devem ser explorados nos projetos para esse tipo de ambiente. Por esse prisma, encoraja-se explorar diferentes cores, texturas, formas e materiais nas características de seus elementos ambientais, e aumentar o número e a diversidade desses elementos na cena para garantir máxima complexidade ambiental.

Por fim, cabe apenas alertar que esses resultados não devem ser tomados de uma maneira simplista, pois corresponde as respostas avaliativas para um determinado conjunto de imagens, população amostral - relativamente pequena - local e época em que foi realizada.

\section{AGRADECIMENTOS}

Os autores deste trabalho agradecem à CAPES (Coordenação de Aperfeiçoamento de Pessoal de Nível Superior) pelo apoio recebido, vindo através de uma Bolsa de Mestrado Acadêmico.

\section{REFERÊNCIAS}

ACIOLI, P. B.; COSTA FILHO, L. "Agradabilidade Percebida em Salas de Aula para o Ensino Superior", p. 42-51. In: Anais do 170 Congresso Internacional de Ergonomia e Usabilidade de Interfaces Humano-Tecnologia e 170 Congresso Internacional de Ergonomia e Usabilidade de Interfaces e Interação Humano Computador. São Paulo: Blucher, 2019.

BERLYNE, D. E. Ends and meanings of experimental aesthetics. Canadian Journal of Psychology, 26, 1972.

BERNARDES, M. Configuração arquitetônica de salas de aula como ambientes promotores do bem-estar. 188p. Dissertação (mestrado) - Universidade Federal de Santa Catarina, Centro Tecnológico, Programa de Pós-Graduação em Arquitetura e Urbanismo, Florianópolis, 2018.

BILSKY, W. A Teoria das Facetas: noções básicas. Estudos de Psicologia, v. 8, n. 3, p. 357-365, 2003.

CANTER, D.; BROWN, J.; GROAT, L. Multiple Sorting Procedure for study conceptual systems. In CANTER, D.; BROWN, J.; BRENNER, M. (Org.). Research Interview: use and approaches. London: Jonh Wiley, 1985.

COSTA FILHO, L. L. "O Enfoque da Teoria das Facetas na Avaliação de Lugares". In: V ENEAC - ENCONTRO NACIONAL DE ERGONOMIA DO AMBIENTE CONSTRUÍDO E VI SEMINÁRIO NACIONAL DE ACESSIBILIDADE INTEGRAL, 2014. Rio de Janeiro. Anais... Rio de Janeiro, PUC-Rio, LEUI/PUC - Rio. 2014.

ELALI, G. A. O ambiente da escola - o ambiente na escola: uma discussão sobre a relação escola-natureza em educação infantil. Estudos de Psicologia 2003, 8(2), 309-319

KAPLAN, S., KAPLAN, R. The experience of nature: A psychological perspective. New York: Cambridge University Press, 1989

KOWALTOWSKI, D. C. C. K; LABAKI L. C.; MIKAMI G. P. Conforto e Ambiente Escolar. Cadernos de Arquitetura. Bauru, DAUP/FAAC/UNESP. 2001. Acesso em 12 de dezembro de 2018. Disponível em: http://www.dkowaltowski.net/1051.pdf

KOWALTOWSKI, D. C. C. K. Arquitetura escolar: o projeto do ambiente de ensino. Oficina de textos, 2011

MARCONI, M. A., LAKATOS, E. M. Técnicas de pesquisa: planejamento e execução de pesquisas, amostragens e técnicas de pesquisas, elaboração, análise e interpretação de dados. 5. ed. São Paulo: Atlas, 2002.

MORAES, A. Ergodesign do Ambiente Construído e Habitado. Rio de Janeiro: IUSER, 2004. 


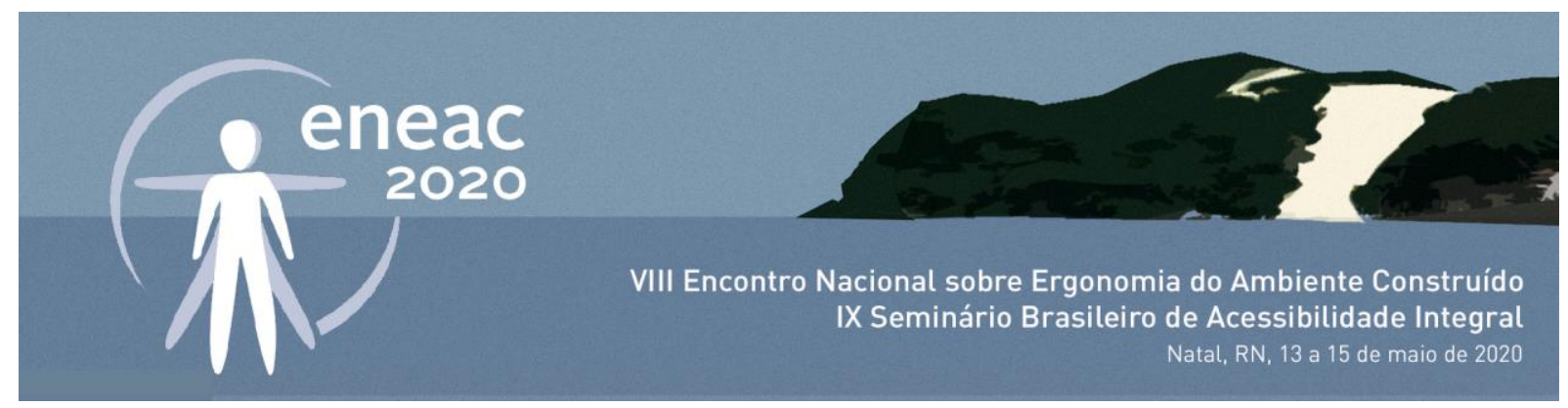

MORAES, A; MONT'ALVÃO, C. Ergonomia: conceitos e aplicações. 4. ed. ampliada. Rio de Janeiro: 2AB, 2009.

NASAR, J. L. (Ed.). Environmental Aesthetics: theory, research, \& applications. New York: Cambridge University Press, 1988. p. 300-320.

The evaluative image of places. In WALSH, W. B.; CRAIK, K. H; PRINCE, R. H. 2nd ed. (Eds.). Person-environment psychology: new directions and perspectives, pp 117-168. New Jersey: Lawrence Erlbaum Associates, 2000.

. Visual quality by design. Michigan: Haworth, Inc., 2008.

OLIVEIRA, G. R.; MONT'ALVÃO, C. R. Metodologias utilizadas nos estudos de Ergonomia do Ambiente Construído e uma proposta de modelagem para projetos de Design de Interiores. Estudos em Design, v. 23, n. 3, p. 150165, 2015.

SARMENTO, T. F. C. S.; VILLAROUCO, V. "AVALIAÇÃO ERGONÔMICA EM AMBIENTES DE APRENDIZAGEM COM RECURSOS TECNOLÓGICOS, COMPARAÇÃo ENTRE ESTUDOS DE CASO DE RECIFE E NÁPOLES", p. 820-831. In: São Paulo: Blucher, 2018.

SANOFF, Henry. School Building Assessment Methods. 2001

SOLOMON, E. Guest Editors' Introduction Facet Theory in Organizational Research. International Studies of Management \& Organization, v. 49, n. 3, p. 233-246, 2019.

WOHLWILL, J. Environmental aesthetics: The environment as a source of affect. In: I. Altmann; J. Wohwill (Eds.), Human behavior and environment, V.1, 37-86, 1976. 